\title{
Are resin-containing pulp capping materials as reliable as traditional ones in terms of local and systemic biological effects?
}

\author{
Elif Pinar BAKIR ${ }^{1}$, Zehra SÜSGÜN YILDIRIM², Şeyhmus BAKIR ${ }^{1}$ and Aydin KETANi ${ }^{3}$ \\ ${ }^{1}$ Dicle University, Faculty of Dentistry, Restorative Dentistry Department, 21280, Sur, Diyarbakir, Turkey \\ ${ }^{2}$ Cukurova University, Faculty of Dentistry, Restorative Dentistry Department, 01330, Balcali, Adana, Turkey \\ ${ }^{3}$ Dicle University, Faculty of Veterinary Medicine, Histology and Embryology Department, 21280, Sur, Diyarbakir, Turkey \\ Corresponding author, Zehra SÜSGÜN YILDIRIM; E-mail: susgunzehra@gmail.com
}

\begin{abstract}
The aim of this study was to compare the local and systemic effects of current pulp capping materials containing resin with those of traditional materials in an animal study. A total of 48 rats were used: a control group ( $n=12)$ (sub-control and negative control), a resin-containing group ( $n=18$ ) (Calcimol LC, Theracal LC, Activa-BioActive Base/Liner), and a traditional group ( $n=18)$ (Biodentine, ProRoot MTA, Dycal). The materials which had been placed in polyethylene tubes were implanted in subcutaneous pockets. The rats were sacrificed at 1, 2, or 4 weeks. Evaluations were made of subcutaneous connective tissue, the left kidney, liver, and blood samples. Of all the study groups, MTA demonstrated biocompatibility at a level close to that of the control groups. Inflammation was observed to be more severe in resin-containing materials, but Activa Base/Liner showed a more successful local and systemic tissue response.
\end{abstract}

Keywords: Pulp capping, Resin-containing materials, Biological effects, Animal study

\section{INTRODUCTION}

Vital pulp treatments aim to protect the vitality and the structural and functional characteristics of pulp tissue. This is based on the capping of unsymptomatic vital pulp tissue exposed because of trauma or decay with a biocompatible material ${ }^{1}$. Compared with lengthy endodontic treatments, these types of treatments have the advantages that they can be more easily and rapidly applied. The basic aim of treatment is to protect the pulp complex by creating a hard tissue barrier over the exposed pulp tissue ${ }^{2)}$.

The materials to be applied should have the ability to form reparative dentin, an antibacterial effect, tissue healing, cell compatibility and lesion restriction ${ }^{2}$. With the introduction of new approaches to vital pulp treatment in recent years, there has started to be research into the effects on live tissue of vital pulp capping materials, especially those containing resin, which are fluid, can be applied with a syringe and are hardened with a light source. In previous studies, the importance has been shown of the evaluation of the local and systemic biological effects which are provided by being able to use these materials safely. According to Culliton et al., stated that systemic toxicity of all biomaterials that contacted blood must be assessed, and the subcutaneous implantation protocol is a reliable method for determining the systemic toxic effects of these biomaterials ${ }^{3)}$. Despite the reliability of the systemic toxicity test that use animal models, observed findings may not be exactly the same for humans. However, these findings must be taken into account regarding the clinical use of the materials.

Color figures can be viewed in the online issue, which is available at J-STAGE.

Received Feb 20, 2021: Accepted Jun 28, 2021

doi:10.4012/dmj.2021-065 JOI JST.JSTAGE/dmj/2021-065
There are currently many vital pulp capping materials available for clinical use. The most commonly used traditional pulp capping material is calcium hydroxide, which stimulates the formation of dentin bridging and has an antibacterial effect. The process of new material development has been accelerated as calcium hydroxide compounds are highly alkaline, and have a cytotoxic effect and inadequate physical characteristics (reaction with water, permeability, etc. $)^{4}$.

One of the first alternative materials developed was mineral trioxide aggregate (MTA), which has demonstrated success with high biocompatibility, the ability to harden in a moist environment, impermeability and bioactivity ${ }^{5}$. The use of white MTA is nowadays preferred rather than grey MTA, which has a longer working period, viscosity, difficulty of use and causes discolouration in the tooth ${ }^{6}$.

To eliminate the MTA indication limitations and to develop the physicochemical characteristics, another pulp capping material that has been presented for use is Biodentine, which is a bioactive technique material based on calcium silicate ${ }^{7}$.

As a result of the addition of resin monomers which are hardened with a light source to materials containing calcium hydroxide and calcium silicate, the hardening properties have been strengthened and problems related to the composite resin binding to the underlying system can be prevented ${ }^{8}$. The most prominent of these materials are Calcimol, which contains calcium hydroxide modified with resin hardened by light, and TheraCal, which contains tricalcium silicate. Despite the high physical properties, low resolution, and ease of use, pulp capping materials which are hardened with a light source may cause cytotoxic effects because of the resin monomer content ${ }^{9)}$. 
In recent years, bioactive dental resins (ActivaBioActive dual cure products), which stimulate mineralization in the tooth-restoration interface by mimicking the physical and chemical properties of teeth, have been introduced to the market. Activa-BioActive Base/Liner presents all the advantages of glass ionomers in a strong and flexible resin matrix. According to the manufacturer's statement, it is chemically bound to the teeth, is impermeable to microleakage, releases calcium, phosphate, and fluoride, and can be re-charged ${ }^{10)}$.

The aim of this animal experimental study was to evaluate the local and systemic biological effects of the currently most preferred resin content (hardened with a light source) and traditional (chemically hardened) vital pulp capping materials and to examine the histopathological findings in subcutaneous connective tissue, liver tissue and kidney tissue.

\section{MATERIALS AND METHODS}

\section{Preparation of materials}

First, the materials freshly prepared according to the manufacturer's instructions were hardened by placement in sterile polyethylene tubes $7 \mathrm{~mm}$ in length and $1.3 \mathrm{~mm}$ in diameter. The properties of the materials used in the study and the hardening reactions are summarized in Table 1.

\section{Implementation of the animal experiment}

Approval for this study was granted by the Dicle University Experimental Animals Research Local Ethics Committee (decision no: 2017-01). The animals used in the study were obtained from Dicle University Health Sciences Research and Application Center. A total of 48 adult male albino rats, each weighing 250-300 gr, were kept in cages in groups of 6 , under a 12 -h lightdark cycle, at standard care conditions with free access to pellet food and drinking water.

Before the surgical procedure, the 48 rats were randomly separated into 3 main groups; the control group (CG) and according to the curing reactions of the study materials, light-cured resin-containing materials group (RCG), and chemically-cured traditional materials group (TG) (Fig. 1).

Under aseptic conditions, anesthesia was applied intramuscularly to all the animals using $50 \mathrm{mg} / \mathrm{kg}$ ketamine hydrochloride (Ketalar, Pfizer, Istanbul, Turkey) and $5 \mathrm{mg} / \mathrm{kg}$ xylaxine hydrochloride (Rompon, Bayer, Şişli, Istanbul). The rats were positioned prone and the back was shaved with clear borders, and

Table 1 Materials used for the study and their properties

\begin{tabular}{|c|c|c|c|c|}
\hline Trade name & Chemical name & Constituents & $\begin{array}{l}\text { Hardening } \\
\text { reaction }\end{array}$ & Manufacturer \\
\hline $\begin{array}{l}\text { Calcimol LC } \\
(\mathrm{CLC})\end{array}$ & $\begin{array}{l}\text { Resin-modified } \\
\text { calcium } \\
\text { hydroxide }\end{array}$ & $\begin{array}{l}\text { Urethane dimethacrylate, Pyrogen silica, } \\
\text { Calcium dihydroxide, 2-Dimethylaminoethyl } \\
\text { methacrylate }\end{array}$ & Light-cure & $\begin{array}{l}\text { Voco, } \\
\text { Cuxhaven, } \\
\text { Germany }\end{array}$ \\
\hline $\begin{array}{l}\text { Theracal LC } \\
\text { (TLC) }\end{array}$ & $\begin{array}{l}\text { Resin-modified } \\
\text { calcium silicate }\end{array}$ & $\begin{array}{l}\text { Portland cement type III, Poly(ethylene glycol) } \\
\text { dimethacrylate, Bis-GMA, Barium zirconate }\end{array}$ & Light-cure & $\begin{array}{l}\text { Bisco, } \\
\text { IL, USA }\end{array}$ \\
\hline $\begin{array}{l}\text { Activa } \\
\text { BioActive-Base/ } \\
\text { Liner } \\
\text { (ABL) }\end{array}$ & $\begin{array}{l}\text { Self-adhesive } \\
\text { dual cured resin } \\
\text { modified glass } \\
\text { ionomer }\end{array}$ & $\begin{array}{l}\text { Diurethane dimethacrylate. bis } \\
\text { (2-(methacryloyloxy) ethyl) phosphate, barium } \\
\text { glass, ionomer glass, polyacrylic acid/maleic } \\
\text { acid copolymer, dual-cure chemistry, sodium } \\
\text { fluoride, colorants }\end{array}$ & Dual-cure & $\begin{array}{l}\text { Pulpdent, } \\
\text { MA, USA }\end{array}$ \\
\hline $\begin{array}{l}\text { Biodentine } \\
\text { (BD) }\end{array}$ & $\begin{array}{l}\text { Calcium silicate } \\
\text { based cement } \\
\text { (Bioactive Dentin } \\
\text { Substitute) }\end{array}$ & $\begin{array}{l}\text { Powder: tricalcium silicate, dicalcium silicate, } \\
\text { calcium carbonate, iron oxide, and zirconium } \\
\text { oxide. Liquid: water, calcium chloride, and } \\
\text { partially modified polycarboxylate }\end{array}$ & Self-cure & $\begin{array}{l}\text { Septodont, } \\
\text { Saint-Maur- } \\
\text { des-fossés, } \\
\text { France }\end{array}$ \\
\hline $\begin{array}{l}\text { ProRoot MTA } \\
\text { (PRMTA) }\end{array}$ & $\begin{array}{l}\text { Mineral trioxide } \\
\text { aggregate }\end{array}$ & $\begin{array}{l}\text { Tricalcium silicate, dicalcium silicate, } \\
\text { tricalcium aluminate, tetracalcium } \\
\text { aluminoferrite, calcium sulphate bismuth oxide, } \\
\text { calcium oxide, silicon oxide, and aluminium } \\
\text { oxide }\end{array}$ & Self-cure & $\begin{array}{l}\text { Dentsply } \\
\text { Tulsa Dental, } \\
\text { Tulsa, } \\
\text { OK, USA }\end{array}$ \\
\hline $\begin{array}{l}\text { Dycal } \\
\text { (DCL) }\end{array}$ & $\begin{array}{l}\text { Calcium } \\
\text { hydroxide }\end{array}$ & $\begin{array}{l}\text { Base Paste: } 1,3 \text {-butylene glycol disalicylate, zinc } \\
\text { oxide, calcium phosphate, calcium tungstate, } \\
\text { iron oxide pigments. Catalyst paste: calcium } \\
\text { hydroxide, N-ethyl-o/p-toluene sulphonamide, } \\
\text { zinc oxide, titanium oxide, zinc stearate, iron } \\
\text { oxide pigments }\end{array}$ & Self-cure & $\begin{array}{l}\text { Dentsply, } \\
\text { CA, USA }\end{array}$ \\
\hline
\end{tabular}


then antisepsis was provided with povidon iodine. In two specified regions in the dosal section, cuts of approximately $1.2 \mathrm{~cm}$ in length were made with a no. 15 sterile surgical knife (Carl Martin, Solingen, Germany). Entering the cut regions with a sterile periostum elevator, two pockets were opened subcutaneously with blunt dissection to a depth of approximately $2 \mathrm{~cm}$. The control group of 12 rats was subdivided into a subcontrol group (sCG, n:6) and a negative control group (nCG, n:6). No tube implantation was made to the $\mathrm{sCG}$ animals and to the $\mathrm{nCG}$, an empty sterile polyethylene tube was implanted. To the RCG and TG, implantation was made of the tubes filled with the materials that had completed the hardening reactions.

The incision sites were then closed with 4/0 silk sutures, and antibacterial Neo-Caf Spray (Intervet Vet Ilac Paz ve Tic Ltd Sti, Istanbul, Turkey) was applied over the sutures. Throughout the period of the study, the rats were monitored in respect of the development of any complications, oedema or infection in the operation region. The groups were separated according to the time to sacrifice of 1,2 , and 4 weeks.

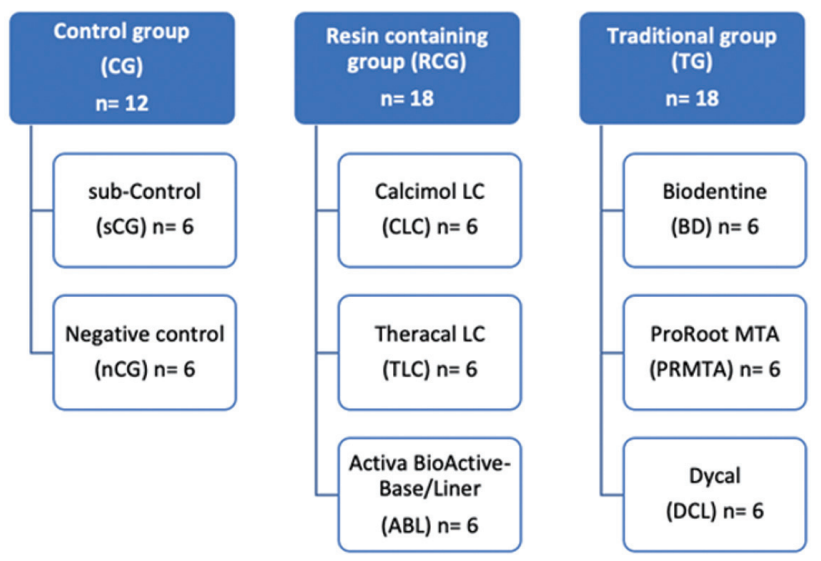

Fig. 1 Diagram illustrating the classification of study groups.

\section{Collection of blood and tissue samples}

The rats were anesthetized with $90 \mathrm{mg} / \mathrm{kg}$ ketamine hydrochloride and $5 \mathrm{mg} / \mathrm{kg}$ xylazine hydrochloride to evaluate the results on 1,2 , and 4 weeks after material implantation. Later, the blood samples collected by intracardiac method was delivered to the biochemistry laboratory with heparinized tubes. Rats were killed by intracardiac exsanguination under anesthesia.

The surrounding connective tissue which had been in contact with the polyethylene tubes was removed. At the same time, the liver and left kidney were removed. The tissue samples from the liver, kidney and connective tissue were placed in 10\% formalin for $48 \mathrm{~h}$, then embedded in paraffin blocks. Slices $5 \mu \mathrm{min}$ thickness were cut with a Leica Rotary microtome, and the preparates were stained with hematoxylin and eosin and Mallory Trichrome for light microscope evaluation.

\section{Histopathological evaluation}

The preparates were examined under a light microscope with a Nikon Eclipse e-400 RSI digital photograph camera, measurements and counts were taken and recorded, and photographs were taken.

The histological evaluation was made in two stages:

1. Evaluation of subcutaneous connective tissue

In the obtained samples of subcutaneous connective tissue, angiogenesis, collagen tissue and fibrosis formation, and subcutaneous inflammatory response (SIR) occurring at the point where the experiment tubes touched the connective tissue were determined. The preparates were evaluated at $\times 20$ magnification by two specialist histologists blinded to the groups. Inflammatory cells (lymphocytes, neutrophils, macrophages, fibroblasts, plasma cells) were counted in an area of $81,206.71 \mu \mathrm{m}$. SIR was scored as shown in Table 2.

2. Evaluation of the liver and left kidney

The samples taken included the periportal and pericentral of the liver and the cortex of the kidney. The liver preparates were examined at $\times 20$ magnification

Table 2 Scoring histopathological evaluation data

\begin{tabular}{|c|c|c|c|c|}
\hline & 0 & 1 & 2 & 3 \\
\hline $\begin{array}{l}\text { Subcutaneous } \\
\text { inflammatory } \\
\text { response }\end{array}$ & $\begin{array}{l}\text { absent: none or few } \\
\text { inflammatory cells }\end{array}$ & $\begin{array}{c}\text { discrete: less than } \\
25 \text { inflammatory } \\
\text { cells }\end{array}$ & $\begin{array}{l}\text { moderate: between } \\
25 \text { and } 125 \\
\text { inflammatory cells }\end{array}$ & $\begin{array}{l}\text { severe: } 125 \text { cells } \\
\text { and more } \\
\text { inflammatory cells }\end{array}$ \\
\hline Angiogenesis & absent & available, very little & available, intensely & - \\
\hline Collagen tissue & absent & available, regular & available, irregular & - \\
\hline Fibrosis & absent & slight & loose & dense \\
\hline $\begin{array}{l}\text { Liver inflammatory } \\
\text { response }\end{array}$ & absent & discrete & moderate & severe \\
\hline $\begin{array}{l}\text { Kidney inflammatory } \\
\text { response }\end{array}$ & absent & discrete & moderate & severe \\
\hline
\end{tabular}


and the kidney preparates at $\times 40$ magnification by two specialist histologists blinded to the groups. The liver inflammatory response (LIR) and the kidney inflammatory response (KIR) were evaluated and scored as "none, mild, moderate, or severe" according to the criteria below.

Liver tissue:

0) None: No findings of inflammation in the periportal and pericentral areas and Remak cell cords observed regular.

1) Mild: mild inflammation, mild lymphocyte infiltration and dilatation only observed in the sinusoids.

2) Moderate: dilatation in the sinusoids together with mild inflammation and mild deterioration in erythrocytes, cell bands, and hepatocytes.

3) Severe: intense inflammation and evident deterioration in cell bands and hepatocytes.

Kidney tissue:

0) None: no inflammation or inflammatory cells and the cortex, tubular, glomerular, and vascular structures observed as normal.

1) Mild: the presence of mild inflammation but normal tubular and glomerular structures.

2) Moderate: mild inflammation together with irregular tubular epithelium, desquamation and normal glomerular structures.

3) Severe: intense inflammation, deterioration in the tubules, dilatation in the vessels, irregular tubular epithelium, desquamaation and vacuolar degeneration in the tubules.

\section{Biochemical analysis}

A spectrophotometer autoanalyzer was used (AU5600 and Beckman kit, Beckman Coulter, Istanbul, Turkey). Blood samples taken into gel tubes (Becton Dickinson, NJ, USA) were centrifuged at 4,000 rpm and serum was obtained in which the levels of alanine aminotransferase (ALT) and aspartate aminotransferase (AST) were analyzed.

\section{Statistical analysis}

Data obtained in the study were analyzed statistically using IBM SPSS vn. 22 software (IBM, Armonk,
NY, USA). Variables were summarized as median (minimum-maximum) or mean \pm standard deviation (SD) values, according to data type. The Kruskal Wallis test was used in the analysis of the variables used in the histopathological scoring, then in the paired group comparisons, the Mann Whitney $U$-test was applied. Biochemical measurements such as AST and ALT were evaluated with the Shapiro-Wilk test if distribution was normal. In the group comparisons, ANOVA one-way variance analysis was applied to variables with normal distribution and the Kruskal Wallis test to variables not showing normal distribution. In all analyses, a value of $p<0.05$ was accepted as statistically significant.

\section{RESULTS}

Statistical results are presented as the light-cured resin-containing group (RCG) and the chemically-cured traditional group (TG) according to the curing reactions. Also, since the results of the $\mathrm{sCG}$ and $\mathrm{nCG}$ groups were statistically the same, they indicate only as CG.

\section{Subcutaneous inflammatory response}

Vascularization, collagen tissue, and fibrogen tissue variables were compared between the groups at all time periods.

A statistically significant difference was found in fibrosis scoring in the 1 st week $(p=0.019)$ (Table 3). While the control group is different from both the resincontaining group $(p=0.010)$ and the traditional group $(p=0.010)$, the scoring in the resin-containing group and the traditional group is similar $(p=0.132)$. Similarly, fibrosis scoring is different between the groups at the 2 nd week ( $p=0.018$ ) (Table 3); while the scoring in the control group was similar to the other groups $(p=0.257, p=0.257$ ), the score in the resin-containing group was lower than the traditional group $(p=0.015)$. The fibrinogen tissue score in the 4th week was higher in the control group compared to the other groups $(p=0.041)$ (Table 3).

A statistically significant difference was found between the groups in the scoring of collagen tissue only at the 2 nd week ( $p=0.011$ ) (Table 3). Although the collagen tissue score in both material groups is similar to the control group, the score is lower in the resin-

Table 3 Subcutaneous inflammatory response

\begin{tabular}{|c|c|c|c|c|c|c|c|c|c|c|c|c|}
\hline & \multicolumn{4}{|c|}{ 1. week } & \multicolumn{4}{|c|}{ 2. week } & \multicolumn{4}{|c|}{ 4. week } \\
\hline & $\begin{array}{c}\text { Subcutaneous } \\
\text { inflammatory } \\
\text { response }\end{array}$ & Angiogenesis & $\begin{array}{l}\text { Collagen } \\
\text { tissue }\end{array}$ & Fibrosis & $\begin{array}{l}\text { Subcutaneous } \\
\text { inflammatory } \\
\text { response }\end{array}$ & Angiogenesis & $\begin{array}{l}\text { Collagen } \\
\text { tissue }\end{array}$ & Fibrosis & $\begin{array}{c}\text { Subcutaneous } \\
\text { inflammatory } \\
\text { response }\end{array}$ & Angiogenesis & $\begin{array}{c}\text { Collagen } \\
\text { tissue }\end{array}$ & Fibrosis \\
\hline Control & $1(1-1)$ & $2(1-2)$ & $2(1-2)$ & $2(1-2)$ & $1(1-1)$ & $2(1-2)$ & $2(1-2)$ & $1(0-3)$ & $1(1-1)$ & $2(1-2)$ & $2(1-2)$ & $1(0-3)$ \\
\hline Resin containing & $1(1-2)$ & $2(0-2)$ & $1(1-2)$ & $0(0-1)$ & $1(1-2)$ & $2(1-2)$ & $1(1-1)$ & $0(0-0)$ & $1(1-1)$ & $2(2-2)$ & $1(1-2)$ & $0(0-0)$ \\
\hline Traditional & $1(1-2)$ & $2(1-2)$ & $2(0-2)$ & $1(0-2)$ & $1(1-2)$ & $2(1-2)$ & $2(1-2)$ & $3(0-3)$ & $1(1-1)$ & $2(2-2)$ & $1.5(1-2)$ & $0(0-0)$ \\
\hline$p$-value* & 0.700 & 0.671 & 0.312 & 0.019 & 0.435 & 0.956 & 0.011 & 0.018 & 0.999 & 0.223 & 0.197 & 0.041 \\
\hline
\end{tabular}

Results were presented as median (minimum-maximum) value. *Kruskal Wallis test was performed. 
containing group compared to the traditional group, but this difference is not statistically significant.

\section{Liver and kidney inflammatory response and AST-ALT} levels

Liver inflammatory response, kidney inflammatory response, AST and ALT levels were compared between the groups at all time periods. AST levels were similar in groups at all time periods ( $p=0.184, p=0.201$, $p=0.765$, respectively) (Table 4). Similarly, ALT levels did not differ in the groups $(p=0.508, p=0.849, p=0.646$, respectively) (Table 4).

While the liver inflammatory response level was found to be similar in the groups in the 1st week $(p=0.082)$, a difference was found in the groups in the $2 \mathrm{nd}$ week $(p=0.018)$ (Table 4). Liver inflammatory response was higher in the resin-containing group compared to the control group $(p=0.007)$. Similarly, at the 4 th week, the liver inflammatory response level was statistically significant $(p=0.024)$ (Table 4), and it was higher in the resin-containing group compared to the control group $(p=0.008)$.

The kidney inflammatory response level was found differently in the groups in the 1st week $(p=0.009)$ (Table 4 ), and the level was higher in the resin-containing group compared to the control group $(p=0.006)$. In the

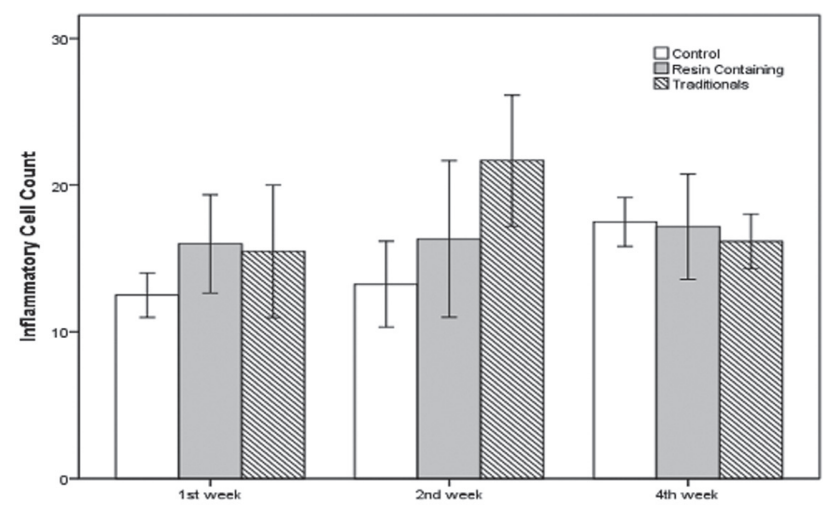

Fig. 2 Comparison of ICC in subcutaneous connective tissue of control, resin-containing, and traditional group according to time variables. 2nd week, kidney inflammatory response levels were similar in the groups $(p=0.109)$ (Table 4$)$. The difference was found in the 4 th week $(p=0.030)$ (Table 4), the level was higher in the resin-containing group compared to the control group $(p=0.010)$.

Results of the histopathological evaluation of subcutaneous connective tissue

1. Control group

At all the time points, the inflammatory cell count (ICC) was at a discrete level (Fig. 2), new vascularization and the formation of collagen fiber was observed. Fibrosis was not observed in $\mathrm{sCG}$, and the connective tissue that was seen to be loose in the first days in $\mathrm{nCG}$ became more dense in subsequent days.

\section{Resin-containing group}

In the Calcimol LC group, ICC was at a moderate level in the 1st and 2nd weeks and fell to a discrete level in the 4th week (Fig. 2). At all the time points, evident vascularization was seen, collagen fiber formation was irregular and weak, and fibrosis had not occurred. Widespread inflammation was seen with a high ICC in week 1 (Fig. 3a) and week 2 (Fig. 3b), and was not observed in week 4.

In the Theracal LC group, although the ICC was at a discrete level at all time points, there was seen to be an increase in the number of inflammatory cells from the 2nd week onwards (Fig. 2). Vascularization was not seen in week 1 but was then seen to be evident in week 2 , and organized in week 4 . There was irregular collagen formation at all the time points. This was seen to be the material with the worst tissue response with inflammation in week 2 (Fig. 3c) and this continued into week 4.

In the Activa Base/Liner group, the ICC was at a discrete level at all time points (Fig. 2). There was vascularization and the formation of collagen tissue at all time points and this was observed to be in a regular form in the 4th week. No fibrosis was seen at any time. Compared to the other materials, there was less lymphocyte infiltration in week 1 and the tissue response and regeneration were observed to be better (Fig. 3d). In the 4 th week, the tissue response was seen to be at a better level compared to the other materials (Fig. 3e).

Table 4 Liver and kidney inflammatory response and AST-ALT levels

\begin{tabular}{|c|c|c|c|c|c|c|c|c|c|c|c|c|}
\hline & \multicolumn{4}{|c|}{ 1. Week } & \multicolumn{4}{|c|}{ 2. Week } & \multicolumn{4}{|c|}{ 4. Week } \\
\hline & Liver & Kidney & AST & ALT & Liver & Kidney & AST & ALT & Liver & Kidney & AST & ALT \\
\hline Control & $0(0-0)$ & $0(0-0)$ & $29.8 \pm 4.8$ & $1.7 \pm 0.9$ & $0(0-0)$ & $0.5(0-1)$ & $28.4 \pm 3.9$ & $2.1 \pm 1.7$ & $0(0-0)$ & $0(0-0)$ & $26.8 \pm 1.8$ & $2.0 \pm 0.5$ \\
\hline Resin containing & $1(0-1)$ & $2(1-3)$ & $32.9 \pm 6.0$ & $2.4 \pm 1.5$ & $1.5(1-3)$ & $2(1-3)$ & $33.2 \pm 6.5$ & $2.4 \pm 1.3$ & $2(1-3)$ & $2(1-2)$ & $27.9 \pm 3.3$ & $2.0 \pm 0.6$ \\
\hline Traditional & $1(0-1)$ & $1(0-2)$ & $36.8 \pm 5.5$ & $2.6 \pm 1.2$ & $1(0-2)$ & $1(0-3)$ & $27.9 \pm 4.4$ & $3.3 \pm 2.7$ & $1(0-3)$ & $1(0-3)$ & $28.1 \pm 3.1$ & $1.7 \pm 0.4$ \\
\hline$p$-value & $0.082^{*}$ & $0.009^{*}$ & 0.184 & 0.508 & $0.018^{*}$ & $0.109^{*}$ & 0.201 & $0.849^{*}$ & $0.024^{*}$ & $0.030^{*}$ & 0.765 & 0.646 \\
\hline
\end{tabular}

Results were presented as median (minimum-maximum) or mean \pm standart deviation. *Kruskal Wallis test was performed, otherwise one way ANOVA. 


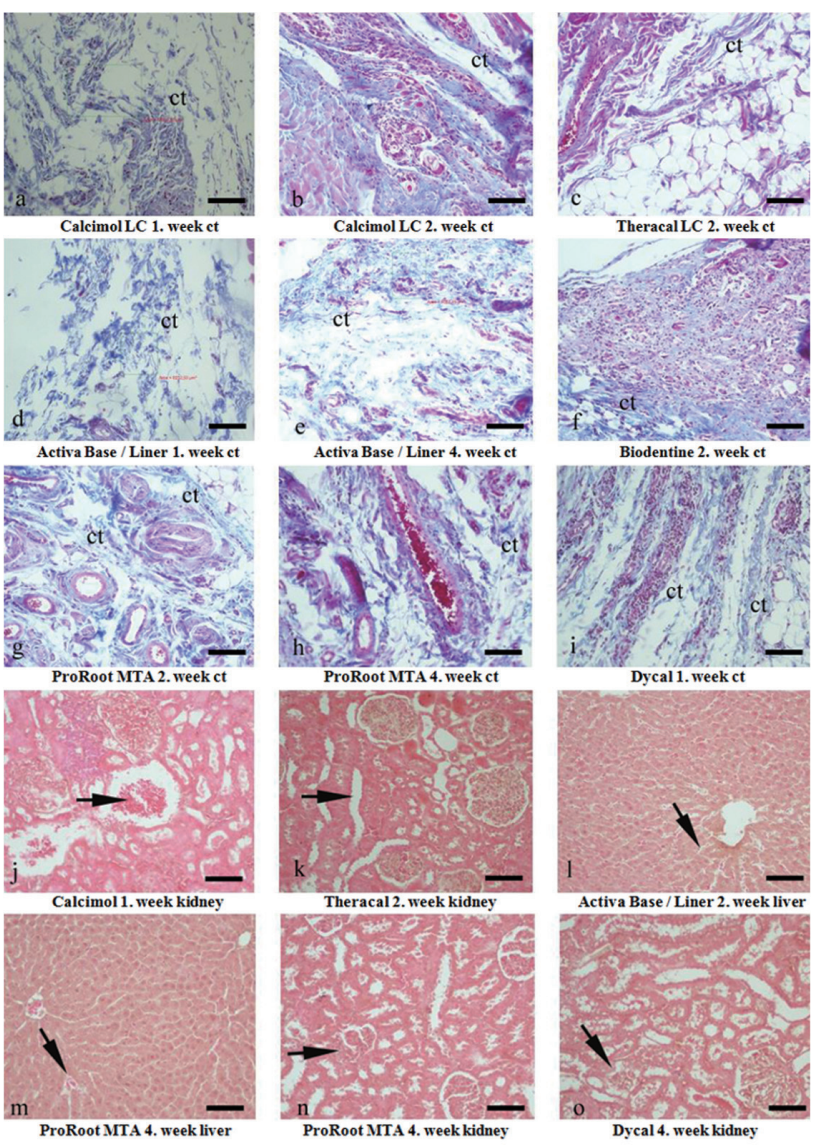

Fig. 3 Photomicrograph showing subcutaneous connective tissue, liver and kidney.

a: Calcimol LC 1. week connective tissue (ct), b: Calcimol LC 2. week connective tissue (ct), c: Theracal LC 2. week connective tissue (ct), d: Activa Base/Liner 1. week connective tissue (ct), e: Activa Base/Liner 4. week connective tissue (ct), f: Biodentine 2. week connective tissue (ct), g: ProRoot MTA 2. week connective tissue (ct), h: ProRoot MTA 4. week connective tissue (ct), i: Dycal 1. week connective tissue (ct), j: Calcimol 1. week kidney, glomerular degeneration (arrow), $\mathrm{k}$ : Theracal 2. week kidney, tubular dilatatiion (arrow), l: Activa Base/Liner 2. week liver sinüzoidal dilatation (arrow), m: ProRoot MTA 4. week liver, liver sinüzoidal dilatation and infilitration (arrow), n: ProRoot MTA 4. week kidney, glomerular degeneration (arrow), o: Dycal 4. week kidney (arrow), a-i: stain: Mallory, Fig. j-o stain: Hematoksilen ve Eosin, Scale bar: 50 micrometer

\section{Traditional group}

In the Biodentine group, the ICC was at a discrete level in weeks 1 and 4, and was moderate in week 2 (Fig. 2). A significant increase in inflammatory cells was determined between weeks 1 and 2 in particular. There was seen to be little vascularization in weeks 1 and 2 , but this increased and was seen in a regular form in week 4. There were few collagen fibers and fibrosis did not occur. In week 2, Biodentine showed a late inflammatory reaction with a high ICC, but in week 4, the tissue response was seen to be better.

In the ProRoot MTA group the ICC was at a discrete level at all time points (Fig. 2). There was observed to be regular and very good vascularization, and organised and regular collagen fiber formation. Fibrous tissue was loose in week 1 but better than in the other groups. In week 2 , there was determined to be partial formation of an organised fibrous capsule. Although cell count was greater, ProRoot MTA was determined to be the material providing the best tissue response in week 2 (Fig. 3g). In week 4, blood vessels were organized and very well formed, collagen fibers were seen to be close to normal, fibrosis occurred, and there was seen to be the shaping of scar tissue associated with the fiber organization (Fig. 3h). While there was more fatty tissue and predominantly loose connective tissue in other materials, there was observed to be less fatty tissue and tighter connective tissue in ProRoot MTA.

In the Dycal group, the ICC level was moderate in week 1 and discrete at the other time points (Fig. 2). There was good vascularization in all the time periods and the formation of collagen fibers was first seen in week 2 . Fibrosis, which was extremely loose in week 1 , was observed as a connective tissue capsule in week 2 . Widespread infiltration together with inflammation was determined in week 1 (Fig. 3i).

Results of the histopathological evaluation of the liver and left kidney

1. Control group

LIR and KIR were absent at all time points.

\section{Resin containing group}

In the Calcimol LC group, LIR was discrete in weeks 1 and 2, and at a moderate level in week 4 . KIR was at a discrete level at all time points. In week 1 , the vessels and sinusoids in liver tissue were observed to be full of erythrocytes (Fig. 3). In the Theracal LC group, LIR was discrete in week 1 and severe in weeks 2 and 4 . KIR was moderate in weeks 1 and 4 and at a severe level in week 2 . Findings of inflammation in the kidney tissue were milder in week 2 than in week 1 , but the sinusoids were observed to be full of erythrocytes (Fig. 3k). In the Activa Base/Liner group, LIR was discrete and KIR was moderate at all the time points. In comparison with the other groups, the findings of inflammation in the liver tissue were milder in week 2 and vascular dilatation was observed to be better (Fig. 31).

\section{Traditional group}

In the Biodentine group, LIR and KIR were discrete at all the time points.

In the ProRoot MTA group, LIR and KIR were absent at all the time points. The histopathological evaluations of the liver (Fig. 3m) and kidney tissue (Fig. $3 \mathrm{n}$ ) in week 4 were seen to be equivalent to those of the control group. In the Dycal group, LIR was discrete in 
week 1 , moderate in week 2 , and severe in week 4 . KIR was moderate in week 1 , and severe in weeks 2 and 4 . In the kidney tissue at 4 weeks, there was observed to be deterioration in the tubular structure, loss of tubular epithelium, and dilatation between the cortex and medulla, and therefore this material met the worst evaluation criteria (Fig. 3o).

\section{DISCUSSION}

In the treatment of vital pulp, biocompatibility is the most important property demanded of the material to be applied directly to the exposed pulp. Biocompatibility is defined as the ability of the material to form an acceptable tissue reaction. The condition for the material to be biocompatible has given rise to the need for cytotoxicity screening experiments. The basis of the biocompatibility evaluation process lies in the evaluation of cell death caused by the material ${ }^{2}$.

However, it is not possible to estimate in-vivo tissue responses with in-vitro cell culture tests. Murray et al. emphasised that to safeguard against potential sideeffects of dental materials new to the market, there is a need for animal experiments and clinical use tests in addition to cytotoxicity tests ${ }^{11)}$.

In the determination of the biocompatibility of pulp capping materials, implantation tests applied to experimental animals have an important role. The implantation test to subcutaneous tissue of rats is one of the most suitable and relatively uncomplicated tests to determine the local effects of dental materials ${ }^{12)}$. The histopathological evaluation process of subcutaneously implanted materials includes the preparation of routine paraffin blocks and histological analysis with light microscopy. The results of these analyses are categorized according to the standardised ISO criteria by measuring the tissue damage and level of regeneration. Inflammatory cell activity is catagorized as "none", "mild", "moderate", or "severe" according to the criteria"13).

These categories are determined according to the degree of presence or absence of localized inflammatory cell lesions, which are predominantly polymorphonuclear leukocytes or mononuclear lymphocytes in the tissue. The inflammatory response is common to all fibrous connective tissues and shows very little change between high types from tissue to tissue or from animal to animal $^{14)}$. Before the clinical use of the experimental material, it must at least have not entered the moderate and severe inflammation categories to be accepted as successful in animal experiments.

As the use of primates, other than humans, is expensive in animal experiments, these studies are by necessity short-term studies. According to the ISO 7405 guidelines, time periods of $3,7,14,30$, and 60 days are generally preferred for subcutaneous implantation tests to test restorative materials ${ }^{15)}$. Moreover, prolonging the implantation period increases the liklihood of determining healing problems and complications associated with the test materials. According to the ISO 10993-1 guidelines, the systemic toxicity of all materials in contact with blood must be evaluated. Systemic toxic effects are determined following subcutaneous implantation of the materials ${ }^{13}$. The use of polyethylene tubes which help fix the material in the tissue to be able to provide appropriate contact between the material and the tissue is extremely common in subcutaneous implantation studies ${ }^{16)}$. Yaltirik et al. suggested using empty polyethylene tubes as a control group in the implantation of dental materials in subcutaneous connective tissue ${ }^{17)}$.

Calcium hydroxide material, which has been established as clinically successful, is the leading traditional pulp capping material, and is often used as the gold standard in experiments. In addition to calcium silicate, calcium phosphate, and calcium aluminatebased materials, and MTA, which were developed as alternatives to calcium hydroxide, the use of pulp capping materials with added resin has come to the fore in recent years ${ }^{18,19)}$. The addition of resin is applied to shorten the hardening time and to develop the traditional materials ${ }^{20)}$. However, the expression of non-polymerized resin monomers from pulp capping materials containing resin has raised concerns about the creation of potential toxic effects ${ }^{21,22)}$.

Parirokh et al. reported that compared to calcium hydroxide, better healing was provided in vital capping applied with calcium silicate-based materials such as Biodentine, proRoot MTA and TheraCal LC in animal experiments $^{23)}$. Yasuda et al. reported that MTA showed no cytoxicity in rat pulp cells, while calcium hydroxide (Dycal) killed almost all cells ${ }^{24}$. It was suggested by Poggio et al. that calcium silicates (ProRoot MTA, MTAAngelus, Biodentine) were less cytotoxic for odontoblast cells than calcium hydroxide (Dycal) ${ }^{25)}$. Furey et al. reported that Dycal had a greater toxic effect on the pulp cells of human teeth than composite resins ${ }^{26)}$. In the current study, Dycal was seen to be the test material demonstrating the worst tissue response at the end of 1 week, whereas ProRoot MTA showed the best tissue response in all the time periods when compared with the other materials. Biodentine showed a late inflammatory reaction with an increase in ICC from the 1st to the 2nd week. It is thought that MTA caused a lower inflammatory response than calcium hydroxide because of the increase in bone morphogenetic protein (BMP-2) production and the ability to stimulate dentinogenesis.

In an in-vitro study by Aranha et al, Calcimol LC was found to be similar to or had a less cytoxic effect than Dycal $^{27)}$. Jeanneau et al. recommended that TheraCal is not used for vital pulp treatments as it was thought to be toxic for pulp fibroblasts ${ }^{9}$. In a study by Lee et al, TheraCal was applied directly over the pulp of canine teeth, and an intense inflammatory reaction was seen in $75 \%{ }^{28)}$. Similarly in the current study, intense local inflammation was seen in the Calcimol LC group, and the worst tissue response was determined in the TheraCal LC group in the 2 nd week.

Karabulut et al. reported that the reactions seen in the subcutaneous connective tissue of rats were similar for MTA, Biodentine, and Activa Base/Liner materials 
and all the materials were well tolerated by the tissues in the 60-day evaluation period of the experiment. However, it was emphasized that the Activa Base/ Liner material could be used safely ${ }^{29}$. The results of the current study similarly showed that Activa Base/Liner could be preferred for clinical use as it showed the lowest ICC rate at 1 week, and the best tissue response in the 4 th week.

There are very few studies in literature that have evaluated the systemic reactions of vital pulp capping materials. One such study by Garcia et al. reported that MTA-based cements showed an inflammatory reaction in the liver and kidneys of rats ${ }^{30}$. In another study by Khalil and Eid, which examined the systemic toxic effects of ProRoot MTA and BioAggregate on the liver and kidneys, a severe inflammatory reaction was observed but this effect reduced within 30 days $^{31}$. In contrast, it has also been seen in evaluations that LIR and KIR were absent in the MTA group and the same characteristics were seen as in the control group. The LIR and KIR were determined at the discrete level in the Biodentine group, whereas these levels had the worst evaluaton criteria in the Dycal group. The reason for this could be that for an antibacterial effect, calcium hydroxide releases hydroxyl ions, which are highly oxidant free radicals in a liquid environment and this affects the mitochondrial activity of cells by spreading away from where they are produced $^{32)}$.

In another study, Khalid and Abunasef reported that MTA elicited more moderate and severe inflammatory reactions than ERRM ${ }^{12)}$. MTA-based materials, contain trace amount of heavy metals, such as iron (Fe), aluminium (Al). The release of these toxic chemicals during the curing time of MTA, which is longer than other pulp coating materials, is shown as the cause of cytotoxicity ${ }^{33}$. It has been suggested that tissue responses to MTA and ERRM differ due to aluminum and other substances in their composition.

In a study of Demirkaya et al., it was stated that the release of Aluminum (Al) while MTA hardens, may pose a potential threat to the organism as $\mathrm{Al}$ is neurotoxic ${ }^{34)}$. Asgary et al. compared the composition of white MTA and gray MTA in their study. Gray MTA has been reported to show higher $\mathrm{Al} 2 \mathrm{O} 3(+122 \%)$ and $\mathrm{FeO}(+1,000 \%)$ levels than white MTA ${ }^{35}$. We think that the reason why the study results of Khalid and Abunasef ${ }^{12)}$. Differ from ours is the difference in content between gray and white MTA.

As stated in a systematic review of in-vitro and in-vivo studies of pulp capping agents by Pedano et al. (2020), there has not been much research related to the cytoxicity of materials containing resin monomers ${ }^{36}$. This could be because the scientific community has accepted the separation of resin monomers from pulp capping materials and that they are toxic. However, this is in conflict with the ongoing development and increasing use of resin-based pulp capping materials. Therefore, the systemic toxicity results of this study, especially of the RCG could fill this gap in literature.

One of the indicators of the systemic effect of any substance that enters the body is the enzyme levels in the blood. Aminotransferases are liver enzymes produced in hepatocyte cells. Aminotransferases are considered a sensitive indicator of liver cell damage. Increase in serum aminotransferase level may occur when the enzyme inside the cell passes into the serum as a result of hepatocellular necrosis. Various drugs, herbs or toxins are known to cause increased aminotransferase levels ${ }^{37)}$. The reason we measured these levels in our study is that we think that pulp capping materials may have a similar effect. However in our study, AST and ALT levels were similar in groups at all time periods.

The study results demonstrated that inflammation in the liver and kidney tissue was more severe with the use of resin-containing materials. The LIR level was moderate in the Calcimol LC group in the 4th week, and severe in the Theracal LC group in the 2nd and 4th weeks. The KIR level was seen to be severe in the 2 nd week. The findings of liver and kidney inflammation were seen to be milder in the Activa Base/Liner group compared to the other resin-containing materials.

The study was based on the use of the lowest number of animals possible in accordance with the 3Rs principle (reduction, refinement, replacement). Therefore statistical data were formed between traditional and resin-containing vital pulp capping materials. The histopathological findings were evaluated for each material. There is a need for clinical use experiments to support the results of this study that was planned with the aim of assisting clinicians on the point of which material should be selected in vital pulp treatments.

\section{CONCLUSION}

The significant results in the statistical evaluation of the local effects of materials showed fibrosis and the formation of new collagen tissue in the control group. In the statistical evaluation of the systemic effects, the LIR and KIR levels in the resin-containing group were determined to be significantly high. The AST and ALT levels were found to be similar at all the time points. Of all the test materials, MTA was seen to have the best systemic and local tissue response, and of the resincontaining materials, Activa Base/Liner was seen to be the most biocompatible material. These results increase the selectability for clinical use of resin-containing materials, which have the advantage of rapid, easy use.

\section{ACKNOWLEDGMENTS}

This study was supported by the coordinator of scientific research projects at Dicle University (Project No: 18.008).

\section{REFERENCES}

1) Schwendicke F, Stolpe M. Direct pulp capping following a carious exposure versus root canal treatment: A costeffectiveness analysis. J Endod 2014; 40: 1764-1770.

2) Poggio C, Ceci M, Beltrami R, Dagna A, Colombo M, Chiesa M. Biocompatibility of a new pulp capping cement. Ann 
Stomatol (Roma) 2014; 5: 69-76.

3) Culliton CR, Meenaghan MA, Sorensen SE, Greene GW, Eick JD. A critical evaluation of the acute systemic toxicity test for dental alloys using histopathologic criteria. J Biomed Mater Res 1981; 15: 565-575.

4) Xia L, Jiang L, Zhu YQ. Cytotoxicity of MTA, Dycal and GIC on human periodontal ligament cells in vitro. Shanghai kou qiang yi xue $2007 ; 16$ : 647-651.

5) Niu LN, Jiao K, Zhang W, Camilleri J, Bergeron BE, Feng HL, et al. A review of the bioactivity of hydraulic calcium silicate cements. J Dent 2014; 42: 517-533.

6) Camilleri J, Pitt Ford T. Mineral trioxide aggregate: A review of the constituents and biological properties of the material. Int Endod J 2006; 39: 747-754.

7) Camilleri J. Characterization and hydration kinetics of tricalcium silicate cement for use as a dental biomaterial. Dent Mater 2011; 27: 836-844.

8) Kayahan MB, Nekoofar MH, McCann A, Sunay H, Kaptan $\mathrm{RF}$, Meraji N, et al. Effect of acid etching procedures on the compressive strength of 4 calcium silicate-based endodontic cements. J Endod 2013; 39: 1646-1648.

9) Jeanneau C, Laurent P, Rombouts C, Giraud T, About I. Light-cured tricalcium silicate toxicity to the dental pulp. J Endod 2017; 43: 2074-2080.

10) Activa (Bioactive restorative material) pamphlet, Pulpdent Co, Watertown. https://www.pulpdent.com/activa-bioactivewhite-paper/. 2019.

11) Murray PE, García Godoy C, García Godoy F. How is the biocompatibilty of dental biomaterials evaluated? Med Oral Patol Oral Cir Bucal 2007; 12: 258-266.

12) Khalil WA, Abunasef SK. Can mineral trioxide aggregate and nanoparticulate EndoSequence root repair material produce injurious effects to rat subcutaneous tissues? J Endod 2015; 41: 1151-1156.

13) ISO 10993. Biological evaluation of dental devices. International Standards Organization 1992.

14) Karanth P, Manjunath MK, Kuriakose ES. Reaction of rat subcutaneous tissue to mineral trioxide aggregate and Portland cement: a secondary level biocompatibility test. J Indian Soc Pedod Prev Dent 2013; 31: 74-81.

15) ISO 7405. Dentistry -Preclinical evaluation of biocompatibility of medical devices used in dentistry - Test methods for dental materials. International Standards Organization 1996.

16) Minotti PG, Ordinola-Zapata R, Midena RZ, Marciano MA, Cavenago BC, Bramante CM, et al. Rat subcutaneous tissue response to calcium silicate containing different arsenic concentrations. J Appl Oral Sci 2015; 23: 42-48.

17) Yaltirik M, Ozbas H, Bilgic B, Issever H. Reactions of connective tissue to mineral trioxide aggregate and amalgam. J Endod 2004; 30: 95-99.

18) Tawil PZ, Duggan DJ, Galicia JC. Mineral trioxide aggregate (MTA): Its history, composition, and clinical applications. Compend Contin Educ Dent 2015; 36: 247-264.

19) Schwendicke F, Brouwer F, Schwendicke A, Paris S. Different materials for direct pulp capping: Systematic review and metaanalysis and trial sequential analysis. Clin Oral Investig 2016; 20: 1121-1132.

20) Camilleri J. Hydration characteristics of Biodentine and Theracal used as pulp capping materials. Dent Mater 2014; 30: 709-715.
21) Qureshi A, Soujanya E, Nandakumar P. Recent advances in pulp capping materials: An overview. Clin Diagn Res 2014; 8: 316-321.

22) Croll TP, Berg JH, Donly KJ. Dental repair material: A resinmodified glass-ionomer bioactive ionic resin-based composite. Compend Contin Educ Dent 2015; 36: 60-65.

23) Parirokh M, Torabinejad M, Dummer PMH. Mineral trioxide aggregate and other bioactive endodontic cements: An updated overview - part I: Vital pulp therapy. Int End J 2018; 51: 177-205.

24) Yasuda Y, Ogawa M, Arakawa T, Kadowaki T, Saito T. The effect of mineral trioxide aggregate on the mineralization ability of rat dental pulp cells: An in vitro study. J Endod 2008; 34: 1057-1060.

25) Poggio C, Ceci M, Dagna A, Beltrami R, Colombo M, Chiesa M. In vitro cytotoxicity evaluation of different pulp capping materials: a comparative study. Arh Hig Rada Toksikol 2015; 66: 181-188.

26) Furey A, Hjelmhaug J, Lobner D. Toxicity of Flow Line, Durafill VS, and Dycal toxicity to dental pulp cells: Effects of growth factors. J Endod 2010; 36: 1149-1153.

27) Aranha AM, Giro EM, Hebling J, Lessa FC, Costa CA. Effects of light-curing time on the cytotoxicity of a restorative composite resin on odontoblast-like cells. J Appl Oral Sci 2010; 18: 461-466.

28) Lee H, Shin Y, Kim SO, Lee HS, Choi HJ, Song JS. Comparative study of pulpal responses to pulpotomy with ProRoot MTA, RetroMTA, and TheraCal in dogs' teeth. J Endod 2015; 41: 1317-1324.

29) Karabulut B, Dönmez N, Göret CC, Ataş C, Kuzu Ö. Reactions of subcutaneous connective tissue to mineral trioxide aggregate, Biodentine ${ }^{\circledR}$, and a newly developed BioACTIVE Base/Liner. Scanning 2020; 1-10

30) Garcia LDFR, Huck C, Magalhães FAC, Souza PPCD, Costa CADS. Systemic effect of mineral aggregate-based cements: Histopathological analysis in rats. J Appl Oral Sci 2017; 25: 620-630.

31) Khalil WA, Eid NF. Biocompatibility of Bio Aggregate and mineral trioxide aggregate on the liver and kidney. Int Endod J 2013; 46: 730-737.

32) Babich H, Sinensky MC. Indirect cytotoxicity of dental materials: A study with Transwell inserts and the neutral red uptake assay. Altern Lab Anim 2001; 29: 9-13.

33) Chen L, Suh BI. Cytotoxicity and biocompatibility of resinfree and resin-modified direct pulp capping materials: A state-of-the-art review. Dent Mater J 2017; 36: 1-7.

34) Demirkaya K, Can Demirdöğen B, Öncel Torun Z, Erdem O, Cetinkaya S, Akay C. In vivo evaluation of the effects of hydraulic calcium silicate dental cements on plasma and liver aluminium levels in rats. Eur J Oral Sci 2016; 124: 75-81.

35) Asgary S, Parirokh M, Eghbal MJ, Brink F. Chemical differences between white and gray mineral trioxide aggregate. J Endod 2005; 31: 101-103.

36) Pedano MS, Li X, Yoshihara K, Landuyt KV, Van Meerbeek B. Cytotoxicity and bioactivity of dental pulp-capping agents towards human tooth-pulp cells: A systematic review of invitro studies and meta-analysis of randomized and controlled clinical trials. Materials 2020; 13: 2670.

37) Ersoy O. Karaciğer Enzim Yüksekliğinin Değerlendirilmesi. [Evaluation of Elevated Liver Enzymes]. Ankara Med J 2012; 12: 129-135. 